ISSN 0258-7122 (Print), 2408-8293 (Online)

Bangladesh J. Agril. Res. 44(1): 79-87, March 2019

\title{
POPULATION ABUNDANCE OF LEAF-EATING CATERPILLARS OF CABBAGE
}

\author{
M. S. SUltanA ${ }^{1}$, M. F. KHATUN ${ }^{2}$, S. N. AlAM ${ }^{3}$ \\ AND M. R. U. MIAH ${ }^{4}$
}

\begin{abstract}
This study was conducted in the experimental field of Entomology Division, Bangladesh Agricultural Research Institute (BARI), Gazipur during October 2014 to April 2015 to know the population abundance of leaf-eating caterpillars, namely prodania caterpillar, Spodoptera litura and diamondback moth (DBM), Plutella xylostella attacking cabbage in Bangladesh. The lowest population of both DBM and prodania larvae per plant was found during November and January whereas the highest population per plant was recorded during September and March 2014 and 2015, respectively. The same trend were observed in case of the adult population in the sex pheromone trap catch. The adult prodania caterpillar population was the highest during October-November and March. During December population declined totally in the month of January. The highest diamondback moth (Plutella xylostella) population was observed during November and March. During the last week of December population again declined entirely which continued until the last week of January. S. litura population was always higher than that of diamondback moth $(\mathrm{DBM})$. There is a positive correlation between the rise of temperature with the population buildup of both S. litura and P. xylostella in cabbage. Especially when the mean temperature declined below $15^{\circ} \mathrm{C}$ then the population of both the pest became nil.
\end{abstract}

Keywords: Cabbage, Spodoptera litura, Plutella xylostella, population abundance, pheromone trap, temperature

\section{Introduction}

Cabbage, Brassica oleracea L., is a popular vegetable in Bangladesh. Cabbage is growing throughout the year due to introduction of heat tolerant varieties. Cabbage is attacked by a group of insect pests. However, two leaf-eating caterpillars, prodenia caterpillar, Spodoptera litura, (F.) (Lepidoptera: Noctuidae) and diamondback moth (DBM), Plutella xylostella, (L.) (Lepidoptera: Plutellidae) are the most destructive pests of cabbage (Nyambo and Pekke, 1995). High population levels of diamondback moth can cause losses in yield up to $90 \%$ (Verkerk and Wright, 1996) worldwide and for many years been considered as the most important pest of cabbages and other brassica crops

\footnotetext{
${ }^{1,2 \& 4}$ Department of Entomology, Bangabandhu Sheikh Mujibur Rahman Agricultural University (BSMRAU), Gazipur-1706, ${ }^{3}$ Entomology Division, Bangladesh Agricultural Research Institute (BARI), Gazipur-1701, Bangladesh.
} 
(Shelton, 2004; Furlong et al., 2013), costing up to 4-5 billion US\$ per year due to damage and control costs (Zalucki et al., 2012). In India, Krishnamoorthy (2003) reported 52\% yield loss of cabbage due to diamondback moth.

Spodoptera litura infested all cruciferous vegetables including cabbage, cauliflower, broccoli, Chinese cabbage, mustard, radish, turnip etc. in Bangladesh and $P$. xylostella has now been reported and documented at least one hundred and twenty-eight countries or territories of the world and is believed to be the most universally distributed of all lepidopterous insect pests (Sarfraz et al., 2006). Shelton (2004) reported that currently, this insect pest is present all over the world wherever the crucifers exist.

The importance of climatic factors in the population dynamics of P. xylostella and S.litura have been emphasized by Vickers et al., 2004. Biology and development of leaf-eating caterpillars are highly dependent on temperature and humidity (Guo and Qin, 2010). Ansari et al., (2010) reported that temperature is a vital factor for the development of $P$. xylostella and S.litura. Life table and population studies showed that besides host plants, rainfall, temperature, humidity and natural enemies greatly influence the survival and reproduction of P. xylostella and S. litura (Haseeb et al., 2001).

S. litura and P. xylostella are a key and destructive pest around the world, but still, little attention has been paid to forecast its population dynamics (Zaluci et al., 2011). Forecasting population dynamics of leaf-eating caterpillars are not easy as many factors influence its abundance and fluctuation (Schellhorn et al., 2008; Muthuthantri et al., 2010). To develop a proper planning for the management of this pest, prediction of the population abundance, it is proper timing of occurrence and level (pest pressure) is highly important (Maelzer et al., 1996). Therefore, the present research was conducted to observe the population dynamics of $S$. litura and $P$. xylostella on cabbage and to determine the effects of temperature, relative humidity on population trend of this pest.

\section{Materials and Methods}

\section{Study site}

The population dynamics of $S$. litura and $P$. xylostella was examined under the sub-tropical climatic zone, present at the experimental field of Entomology Division, BARI, Gazipur conducted during October 2014 to April 2015. The area was situated at $24.09^{\circ}$ North latitude and $90.26^{\circ}$ East longitude with an elevation of 8.4 meters from the sea level.

\section{Parameters and design of the study}

Experiments were laid down in a randomised complete block design (RCBD) having an experimental unit size of 10 meters in width and 10 meters in length transplanted with 40 days old 'Atlas-70'variety of cabbage. Each experimental 
unit consisting of forty (40) cabbage plants, having five (5) rows and every row consisted of eight (8) plants. Plant to plant distance of cabbage was about $60 \mathrm{~cm}$ and row to row distance was $60 \mathrm{~cm}$. For studying population dynamics of leafeating caterpillars, each experimental unit was replicated three times under the same experimental conditions. For documentation of population dynamics, standard agronomic practices, including normal weeding, irrigation practices, fertilisation and sanitation etc. except plant protection measures were followed as per recommended package of practices (Rashid, 1999) in the cabbage fields.

\section{Data collections}

The population of $S$. litura and $P$. xylostella larvae was recorded from two weeks after sowing at weekly intervals and continued until the harvest. The number of adult population of $S$. litura and $P$. xylostella recorded by sex pheromone traps. Bangladesh Agricultural Research Institute (BARI) developed water traps and Ispahani Agro Ltd. pheromone lures were used for adult population monitoring. On the other hand, mean number of larvae were examined and recorded in the field by visually counting at harvest cabbage plant. The collected data were pooled over the cropping season. The infested and healthy yield data were also recorded. Data regarding maximum and minimum temperature, relative humidity and rainfall were collected from Meteorological Department, BARI, Gazipur. Correlation of population fluctuation of prodania caterpillar and diamondback moth (DBM) was done with weather parameters.

\section{Results and Discussion}

\section{A. Results}

The mean population of both leaf-eating caterpillars varied in different months from September 2014 to March 2015. Pest appeared in the first-week after transplanting of 40 days old cabbage seedlings to the field in September. The lowest population of both $P$. xylostella and S. litura larvae per plant was found on November 2014 and January 2015, whereas the highest population per plant was recorded during September 2014 and March 2015, respectively (Table 1). This trend of the population increase continued during September 2014 and March 2015 and decline of population noticed during November to January, when the temperature was below $15^{\circ} \mathrm{C}$.

It is observed from the result of pheromone trap catches that $S$. litura adult population was the highest during October-November and March. During December the population declined and became nil during January (Fig. $1 \& 2$ ). The highest $P$. xylostella adult population was observed during November and March. During the last week of December the population became nil which continued till the last week of January (Fig. 1 \& 2). Especially when the mean temperature declined beyond $15^{\circ} \mathrm{C}$ then the population of both the pest became nil (Fig. 2). S. litura population was always higher than P. xylostella population in the study area. 
Table 1. Population dynamics of both $P$. xylostella and $S$. litura larvae on cabbage plant during 2014-2015

\begin{tabular}{c|c|c|c|c|c}
\hline $\begin{array}{c}\text { Date } \\
\text { (2014-2015) }\end{array}$ & $\begin{array}{c}\text { Number of } \\
\text { P. } \text { xylostella } \\
\text { (Mean } \pm \text { SE) }\end{array}$ & $\begin{array}{c}\text { Number of } \\
\text { S. litura } \\
\text { (Mean } \pm \text { SE) }\end{array}$ & $\begin{array}{c}\text { Temperature } \\
{ }^{\circ} \mathbf{C} \text { (Max.) }\end{array}$ & $\begin{array}{c}\text { Temperature } \\
{ }^{\circ} \mathbf{C} \text { (Min.) }\end{array}$ & RH\% \\
\hline 28 Sep 2014 & $2.7 \pm 0.14$ & $4.5 \pm 0.20$ & 34.56 & 20.23 & 80 \\
12 Oct 2014 & $2.2 \pm 0.10$ & $3.1 \pm 0.23$ & 34.23 & 24.25 & 75 \\
26 Oct 2014 & $2.6 \pm 0.02$ & $3.8 \pm 0.41$ & 29.59 & 22.53 & 73 \\
10 Nov 2014 & $0.6 \pm 0.02$ & $2.7 \pm 0.13$ & 30.45 & 22.24 & 72 \\
24 Nov 2014 & $0.9 \pm 0.07$ & $2.7 \pm 0.13$ & 32.23 & 21.25 & 73 \\
08 Dec 2014 & $1.4 \pm 0.11$ & $2.3 \pm 0.12$ & 30.25 & 19.20 & 80 \\
22 Dec 2014 & $1.2 \pm 0.05$ & $1.2 \pm 0.03$ & 20.07 & 15.32 & 81 \\
05 Jan 2015 & $0.7 \pm 0.05$ & $1.3 \pm 0.17$ & 29.22 & 19.23 & 83 \\
19 Jan 2015 & $0.6 \pm 0.10$ & $2.6 \pm 0.24$ & 28.36 & 17.45 & 82 \\
02 Feb 2015 & $1.2 \pm 0.08$ & $2.2 \pm 0.06$ & 29.51 & 15.45 & 78 \\
16 Feb 2015 & $1.02 \pm 0.18$ & $3.1 \pm 0.17$ & 21.82 & 15.23 & 78 \\
02 Mar 2015 & $2.2 \pm 0.09$ & $4.3 \pm 0.29$ & 25.98 & 16.24 & 70 \\
16 Mar 2015 & $2.7 \pm 0.17$ & $5.5 \pm 0.28$ & 23.12 & 15.76 & 70 \\
30 Mar 2015 & $2.0 \pm 0.15$ & $4.8 \pm 0.66$ & 26.45 & 16.23 & 65 \\
\hline
\end{tabular}

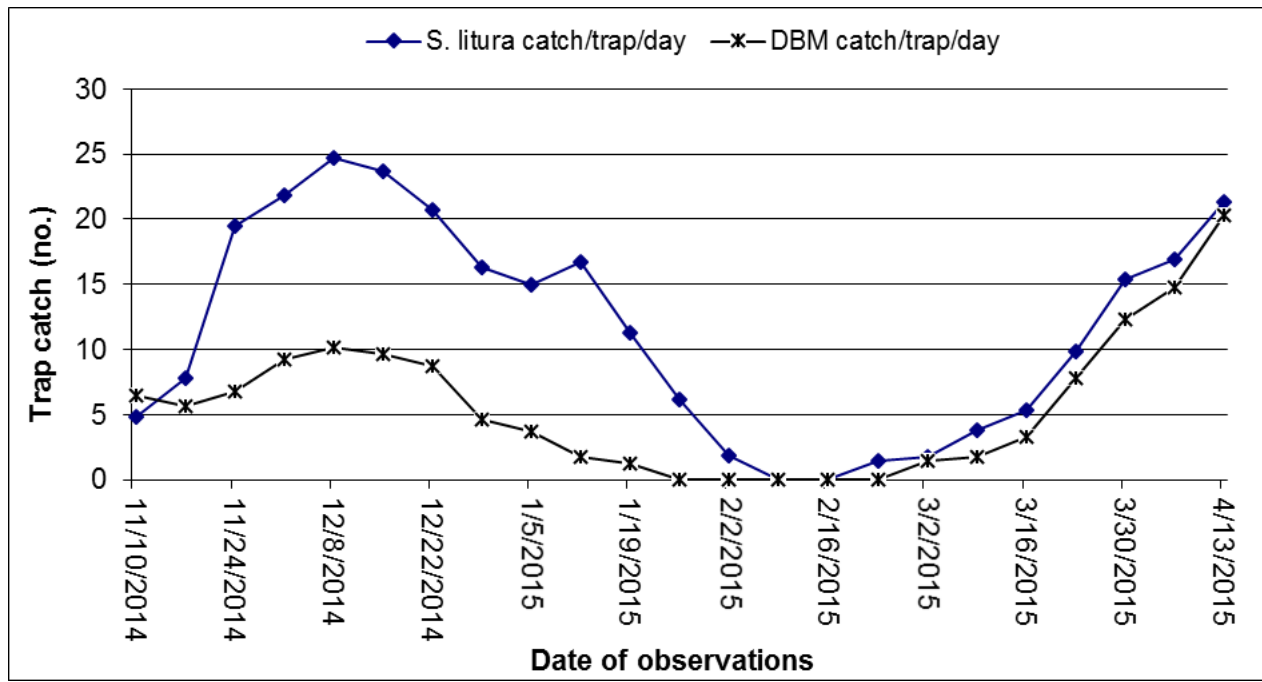

Fig. 1. Population fluctuation of $S$. litura and $P$. xylostella during the study period on the basis of pheromone trap catch. 


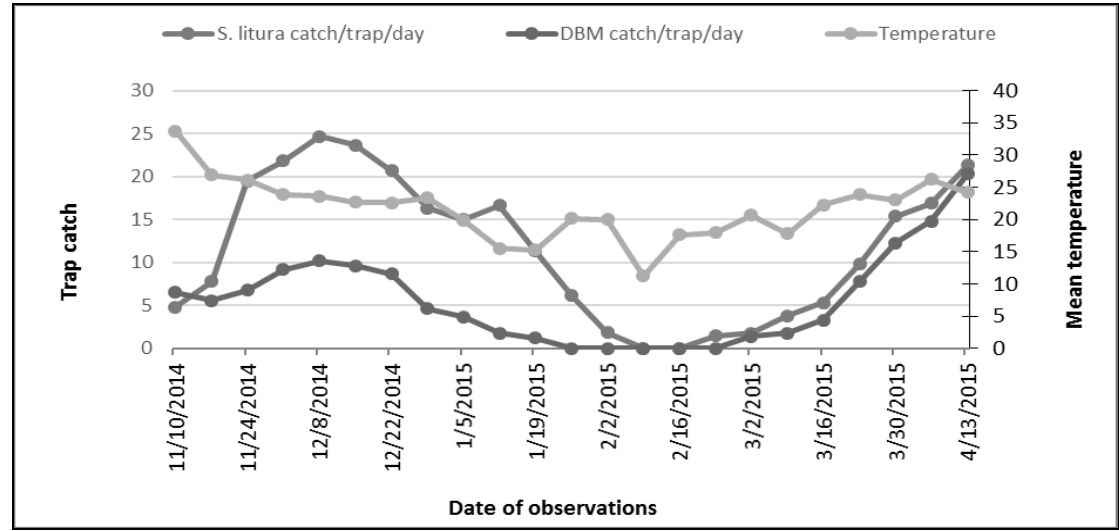

Fig. 2. Population fluctuation of $S$. litura and $P$. xylostella in relation to temperature as these leaf eating caterpillar adults caught by pheromone trap.

There is a positive correlation between temperature rise with the population buildup of both $S$. litura and $P$. xylostella in cabbage (Figure $3 \& 4$ ).

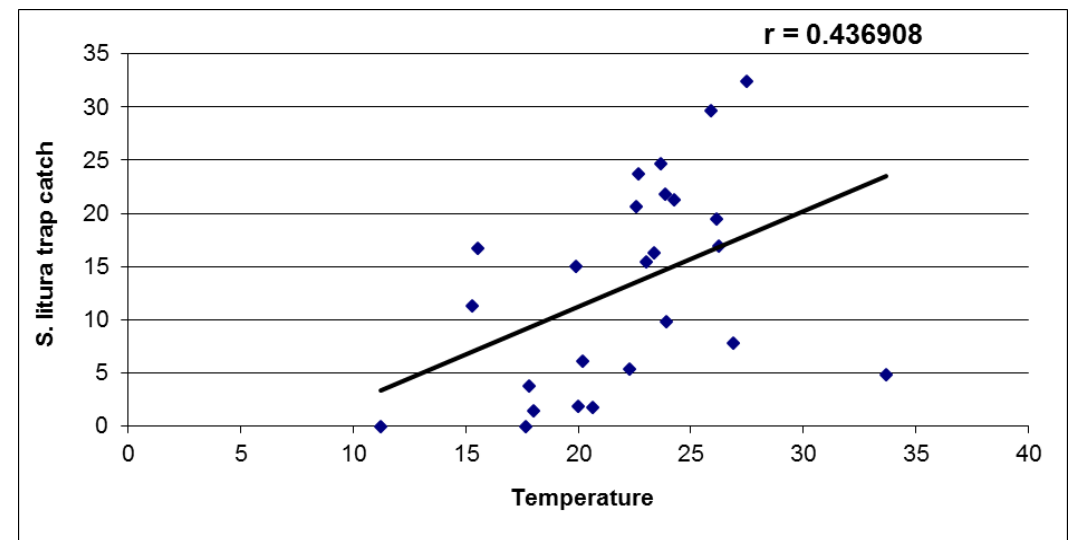

Fig. 3. Correlation between $S$. litura trap catch with the increase of temperature.

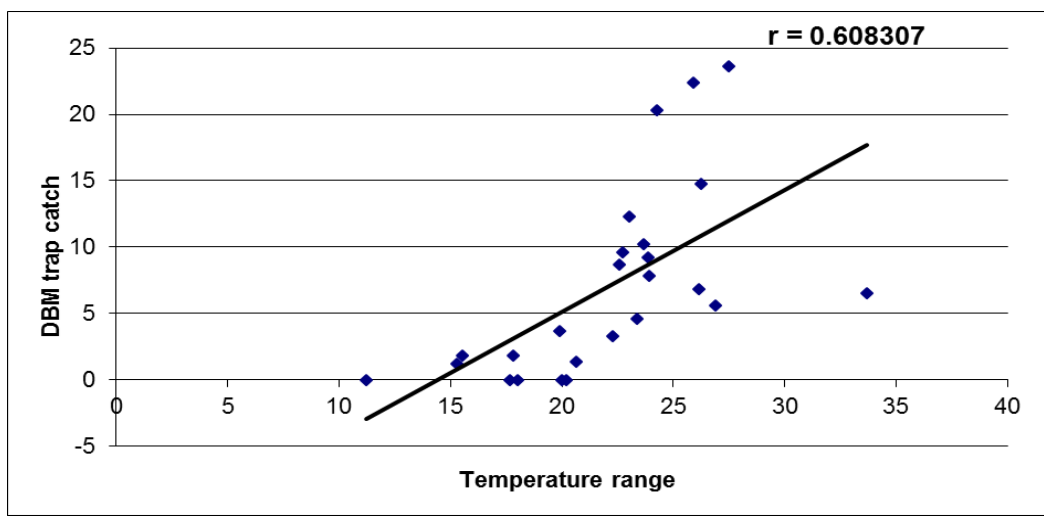

Fig. 4. Correlation between $P$. xylostella trap catch with the increased temperature. 


\section{B. Discussion}

Our studies showed that the incidence of leaf-eating caterpillar Plutella larvae was lowest in the month of November and January and the highest population was found in the month of September and March. Similarly, Ahmed et al. (2015) revealed that the highest population of larvae per cauliflower plant was recorded in September and the lowest was observed in July. The population of the $P$. xylostella showed flare up in the month of August and September (Ahmed and Ansari, 2010).

Our findings were in conformity with the reports of Hasanshahi et al. (2013) who reported that $P$. xylostella population appears at the beginning of the cauliflower season and shortly after transplantation of the seedlings in the field. Patra et al. (2013) stated that $P$. xylostella attacked the crop about one month after transplanting in the field. There was a gradual increase in the population density of S. litura after transplantation. It was found that $P$. xylostella was available in the field from July to November (cropping season) with a mean temperature range of $37^{\circ} \mathrm{C}$ (max.) in July to $7^{\circ} \mathrm{C}$ (mini.) in November, thus indicating that it can survive in a wide range of temperatures (Mohammed et al., 2004). Liu et al. (2000) stated that $P$. xylostella remained active throughout the year in China at a daily minimum temperature in January below $2^{\circ} \mathrm{C}$ to a daily maximum temperature in July rises above $35^{\circ} \mathrm{C}$. $P$. xylostella is distributed in the wide range of temperature from the tropics to cool regions all over the world (CAB International, 2000). Lower relative humidity, higher temperature and lower total rainfall, seem to favour $P$. xylostella population build up (Hemchandra and Singh, 2007). Thus, our result indicate that temperature showed positive correlation with population buildup of S. litura and P. xylostella in cabbage. Likewise, Venkateswarlu et al. (2011) reported that among different climatic tools, the maximum and minimum temperature had a significant positive correlation whereas percent relative humidity showed significant negative correlation with P. xylostella population.

Fund et al. (2015) revealed that the development rate as a function of temperature increased linearly for all the immature stages of $S$. litura until approximately 34 $36^{\circ} \mathrm{C}$, after which it became nonlinear. Seasonal abundance of diamondback moth recorded on cabbage in India revealed that the infestation of diamondback moth (larva) was first recorded on 31 January with an initial population of $0.20 /$ plant. The population increased gradually in successive weekly counts and reached a peak of 12.05/plant on 27th March and thereafter (Goudegnon et al., 1999). They also observed that diamondback moth population attained its peak during February and March. The maximum population of diamondback moth in the month of March was also reported by Kumar et al. (2007), Vanlaldiki et al. (2013) and Venkateswarlu et al. (2011) which are in agreement with the present findings. Temperature is recognized as the most important environmental factor influencing development and survival of insects. The relationship between 
temperature and development of $P$. xylostella has also been studied in other countries (Shirai, 2000; Liu et al., 2002; Mohandass and Zalucki, 2004; Golizadeh et al., 2008). In our studies, we also found that temperature is one of the most important factor for development of both S. litura and P. xylostella populations. The highest population of both $S$. litura and $P$. xylostella per plant was recorded during September and March and the lowest was found November and January with a mean temperature range of $34^{\circ} \mathrm{C}$ in September to $15^{\circ} \mathrm{C}$ in December. In addition, pheromone trap results showed that the population of leaf-eating caterpillars increased when temperature was high moreover the population declined beyond temperature $15^{\circ} \mathrm{C}$, consequently, indicates that it can persist in a wide range of temperature.

It can be concluded that the attack of both $S$. litura and $P$. xylostella in cabbage commenced during the first week after transplantation of cabbage seedling. The lowest population of both P. xylostella and S. litura larvae per plant was found on November to December whereas highest population per plant was recorded during October and March and the highest infestation was recorded from November and March. A positive correlation was observed between the populations of $P$. xylostella and S. litura and temperature. The influence of temperature on development and survival of the diamondback moth may affect the population dynamics of the pest.

\section{Reference}

Ahmad, B., A. U. R. Saljoqi, M. Saeed, F. Ullah and I. A. Khan. 2015. Population dynamics of Plutella xylostella (L.) in cauliflower and its correlation with weather parameters at Peshawar, Pakistan J. Entomol. Zool. Stud. 3: 144-148.

Ahmad, T. and M. S. Ansari. 2010. Studies on seasonal abundance of diamondback moth, Plutella xylostella (L.) on cauliflower crop. J. Plant. Prot. Res. 50:3.

Ansari, M. S., T. Ahmad and H. Ali. 2010. Effect of Indian mustard on feeding, larval survival and development of Plutella xylostella at constant temperatures. Entomol. Res. 40:182-188.

CAB International. 2000. Crop protection compendium, global module (CD-ROM), 2nd ed. CAB, Wallingford, UK.

Fund, B. B., N. T. Sul, S. K. Bal and P. S. Minhas. 2015. Temperature impacts on the development and survival of common cutworm (Spodoptera litura): Simulation and visualization of potential population growth India under warmer temperatures through life cycle modelling and spatial mapping. Plos One. 10: 0124682.

Furlong, M. J., D. J. Wright and L. M. Dosdal. 2013. Diamondback moth ecology and management: Problems, Progress and Prospects. Ann. Rev. Entomol. 58:517-541.

Golizadeh, A. K. Kamali, Y, Fathipour, H, Abbsipour, 2008. Spatial distribution and developing optimum sample size plans for Plutella xylostella infestation. In: Endure International Conference "Diversifying Crop Protection", France, 13-15 October 2008, Congress Palace of La Grande Motte, Montpellier, France. ENDURE. http://www.endure-network.eu/international_conference_2008. 
Goudegnon, A. E., A. A. Kirk and D. Bordat. 1999. Status of P. xylostella (L.) and Cotesiaplutellae (Kurdjumov) in Benin. In: Proceedings of the Fifth International Conference on Pests in Agriculture, Part 3, Montpellier, France. Pp. 679-687.

Guo, S. and Y. Qin. 2010. Effects of temperature and humidity on emergence dynamics of Plutella xylostella (Lepidoptera:Plutellidae). J. Econ. Entomol. 103:2028-2033.

Hasanshahi, G., H. Abbasipour, A. Askarianzadeh, J. Karimiand, F. Jahan. 2013. Seasonal population fluctuations of the diamondback moth, Plutella xylostella $(\mathrm{L}$. (Lepidoptera: Plutellidae) on different cauliflower cultivars. Archi. Phytopath. Plant. Prot. 46:1136-1149.

Haseeb, M, Y. Kobori, H. Amano and H. Nemoto. 2001. Population Density of Plutella xylostella (Lepidoptera: Plutellidae) and its Parasitoid Cotesia plutellae (Hymenoptera: Braconidae) on two varieties of cabbage in an urban Environment. App. Entomol. Zool.36:353-360.

Hemchandra, O. and T. K. Singh. 2007. Population dynamics of DBM, Plutella xylostella (L.) on cabbage agroecosystem in Manipur. Indian J. Entomol. 69:154-61.

Krishnamoorthy, A. 2003. IPM package for cabbage with safe pesticide residue. IIHR, Bangalore, India. 8p. (Extension folder - 05).

Kumar, P., C. S. Prasad, and G. N. Tiwari. 2007. Population intensity of insect pests of cabbage in relation to weather parameters. Ann. Plant. Prot. Sci. 15: 245-246.

Liu, S. S., F. Z. Chen and M. P. Zalucki. 2002. Development and survival of the diamondback moth (Lepidoptera: Plutellidae) at constant and alternating temperatures. Environ. Entomol. 31: 221-231.

Liu, S. S., X. Wang, S. Guo, J. He and Z. Shi. 2000. Seasonal abundance of the parasitoid complex associated with the diamondback moth, Plutella xylostella (Lepidoptera: Plutellidae) in Hangzhou, China. Bull. Entomol. Res. 90:221-231.

Maelzer, D. A., M. P. Zalucki and R. Laughlin. 1996. Analysis of historic light trap data for Helicoverpa punctigera: forecasting the size of the pest population. Bull. Entomol. Res.86:547-557.

Mohammed, K., F. R. Randall, P. Griffin, G. Carner and C. S. Gorsuch. 2004. Diamondback Moth (Lepidoptera: Plutellidae) Population Density and Parasitism by Diadegma insulate on Collard in South Carolina. J. Agril. Urban. Entomol. 21:164170.

Mohandass, S. and M. P. Zalucki. 2004. DBM development: are we measuring the right temperatures? Pp.117-122. In The Management of the Diamondback Moth and Other Crucifer Pests: Proceedings of the Fourth International Workshop. Victoria, The Regional Institute.

Muthuthantri, S., D. A. Maelzer, M. P. Zalucki and A. R. Clarke. 2010. The seasonal phenology of Bactrocera tryoni (Froggatt) (Diptera: Tephritidae) in Queensland. Australian J. Entomol. 49:221-233.

Nyambo, B.T. and A. Pekke. 1995. Brassica Pest Management. In Proc. of the Brassica planning workshop: East and South Africa Region. Lilongwe, Malawi, May 15-18.

Patra, S., V. W. Dhote, S. K. F. Alam, B. C. Das, M. L. Chatterjee and A. Samanta. 2013. Population dynamics of major insect pests and their natural enemies on cabbage under the new alluvial zone of West Bengal. J. Plant. Prot. Sci. 5:42-49. 
Rashid, M. M. 1999. "Shabjibiggayan (In Bengali)". Rashid Publishing House, 94, Old DOHS, Dhaka-1206. p. 233.

Sarfraz, M., L. M. Dosdall and B. A. Keddie. 2006. Diamondback moth host plant interactions: implications for pest management. Crop Prot. 25:625-639.

Schellhorn, N. A., S. Pierce, F. J. J. A. Bianchi, D. Williams and Zalucki, M. P. 2008. Designing landscapes for multiple outcomes in broad-acre environments. Australian J. Exp. Agril. 48:1549-1559.

Shelton, A. M. 2004. Management of the diamond back moth; deja vu all over again? In: Endersby N, Ridland PM. (Eds.) the management of diamond back moth and other crucifer pests, Pp. 3-8. Proceedings of the $4^{\text {th }}$ international workshops on the diamond back moth, 26-29 Nov 2001, Melbourne, Australia.

Shirai, Y. 2000. Temperature tolerance of the diamondback moth, Plutella xylostella (Lepidoptera: Yponomeutidae) in tropical and temperate regions of Asia. Bull. Entomol. Res.90: 357-364.

Vanlaldiki, H., M. P. Singh and R. Lalrinsanga. 2013. Effect of staggered planting on the seasonal abundance of diamond back moth (Plutella xylostella Linn.) on cabbage under north eastern hill zone, imphal. The Bioscan. 8: 1211-1215.

Venkateswarlu, V., R. K. Sharma, S. Chander and D. D. Singh. 2011. Population dynamics of major insect pests and their natural enemies in cabbage. Ann. Plant. Prot. Sci. 19: 272-277.

Verkerk, R. H. J. and D. J. Wright. 1996. Multi trophic interactions and management of the diamondback moth: a review. Bull. Entomol. Res. 86: 205-216.

Vickers, R. A., M. J. Furlong, A. White and J. K. Pell. 2004. Initiation of fungal epizootics in Diamondback moth populations within a large field cage: proof of concept of auto dissemination. Entomol. Exp. App. 111:1-17.

Zalucki, M. P. and M. J. Furlong. 2011. Predicting outbreaks of a migratory pest: an analysis of DBM distribution and abundance revisited pp. 8-14. Proceedings of the Sixth International Workshop, AVRDC. The World Vegetable Center, Shanhua, Taiwan.

Zalucki, M. P., A. Shabbir, R. Silva, D. Adamson, S. S. Liu and M. J. Furlong. 2012. Estimating the economic cost of one of the world's major insect pests, Plutella xylostella: just how long is a piece of string? J. Econ. Entomol.105: 1115-1129. 
